\title{
DNA Traceability System for Meat: A National Project of the Swiss Meat Industry
}

\author{
Heinrich Bucher*
}

\begin{abstract}
Swiss meat is popular in Switzerland and the Swiss consumers have great confidence in it. In order to maintain and deepen this confidence the Swiss meat industry has decided to introduce in spring 2018 a national and independent system of DNA traceability for the proof of origin of Swiss meat. With the new traceability system, it will be possible at any time to show that meat and meat products with the declaration of Swiss origin indeed stem from Swiss animals that have been kept and slaughtered in Switzerland. Due to this unequivocal proof of origin, transparency and security for the declaration of Swiss meat will be increased and the potential for cases of fraud will be minimised.
\end{abstract}

Keywords: DNA · Food fraud · Proof of origin · Swiss meat · Traceability

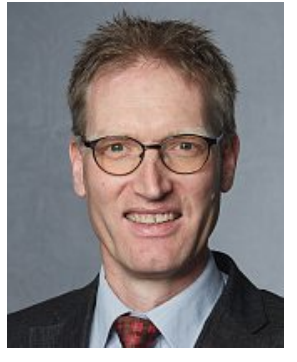

Heinrich Bucher holds a degree in Agricultural Science, ETHZurich and since 2008 is the Director of Proviande, the industry organisation for Swiss meat production. Before that he was Head of animal production at Migros-GenossenschaftsBund (1991-1999) and Head of the department of production, marketing and ecology of the Swiss Farmer's Union (1999-2008). Currently he is Vice-president of AgroMarketing Suisse (AMS) und a member of the Board of the Swiss Association for Animal Sciences (SVT)

\section{Introduction}

In Switzerland about $51 \mathrm{~kg}$ (retail weight) of meat and meat products are consumed annually per head. ${ }^{[1]}$ Hereby, consumers pay close attention to the Swiss origin of meat and emphasize the excellent Swiss standards concerning animal welfare, sustainability, quality and product safety. In order to be able to meet Swiss demand for meat, around $20 \%$ of the consumed quantity must be import-

${ }^{\star}$ Correspondence: H. Bucher ed.[1] Hence, Swiss meat is competing with imported meat, with increasing price pressure. As a consequence, cases of fraud with false declarations have occurred in the past, which must be actively prevented. A reliable declaration of meat origin thus has a high value for the meat industry: the trust of consumers is its capital!

\section{Objectives and Benefits}

In 2017, the Swiss meat industry decided to establish a national and independent system of DNA traceability for the proof of origin of Swiss meat, according to the motto: declared Swiss meat is Swiss meat. By increasing transparency, the consumer's confidence should be strengthened and the potential for fraud minimized.

The system of DNA traceability will strengthen the brand Swiss meat with the added value that the declared origin of Swiss meat can be tested and proven at any time. This creates security and strengthens the confidences of the consumers, likewise having a positive effect on purchase decisions and thereby on the demand. Therefore, the entire value chain of meat will be strengthened sustainably.

\section{Ownership and Technology Partner}

Owner of the system of DNA traceability in Switzerland is Proviande, the organization of the Swiss meat industry. [2] It unites the most important organizations and companies along the meat value chain, from the producers to livestock trade, abattoirs and processing plants, as well as retailers, gastronomy and consumers. Proviande is entrusted with the business management of the system of DNA traceability and has the data ownership and data sovereignty.

Our technology partner is IdentiGEN Ltd. ${ }^{[3]}$ As the first worldwide provider of a successful system of DNA traceability this partner has a large industrial and scientific know how as well as the most recent DNAbased technologies. In order to realize the Swiss project, IdentiGEN Switzerland AG was founded with a laboratory in Schlieren (Switzerland).

\section{Technology}

Animal individuals differ from each other on different biological levels. The most fundamental of these levels, DNA (deoxyribonucleic acid) is present not only in the living animal but also in each piece of meat or meat product of the original animal.

Already in the 1980s techniques for distinguishing individuals due to differences in their respective DNA were described ('genetic finger printing').[4] In recent years these techniques have been further developed and are used routinely in the human area (e.g. forensics, ancestry tests) as well as in animal breeding (genomics). ${ }^{[4]}$

In analogy to forensics, in the planned program DNA analysis will be used to test whether two samples originate from one single individual.

\section{DNA Traceability System}

In a first step the proof of origin is realized by DNA analysis of beef and veal. After successful introduction and establishment of the system, pork and further 
animal species will be included in the system in a further step.

In the slaughterhouses, a reference sample of each cattle will be taken and subsequently analysed in the laboratory. The bar code of the sample carrier will be scanned and assigned to the ear tag of the respective animal. A comparative search with the national animal movement database will allow to check the Swiss origin and history of the animals. The DNA profiles will be stored in a database. With the help of market monitoring control samples will be purchased in the retail trade, in specialty stores and in the gastronomy, and their DNA will also be analysed and stored in the data base.

A comparison of the results of the monitoring samples with data from the reference database allows a reliable statement: Swiss meat, yes or no. In addition, it will be possible to check the declaration of labelled meat from special production programs (Fig. 1).

\section{Market Monitoring}

The establishment of market monitoring for the collection of control samples in the marketplace takes place in two phases and includes in its final stage the retail trade, wholesale trade, meat specialty stores and gastronomy.

The first phase starts four months after the initial sampling of reference materials in the slaughter houses. This allows for sufficient preparatory work in order to correctly introduce and guarantee the processes in the slaughterhouses. In addition, in this way also a longer storage of the meat is taken into account. In phase 1, during 15 months only control samples of fresh muscle meat will be taken in the retail trade. This ensures that meat from frozen storage for which no reference samples exist yet will not be sampled in the first phase and can be sold/turned over in the meantime.

After 19 months, phase 2 of the marketing monitoring starts. From this point

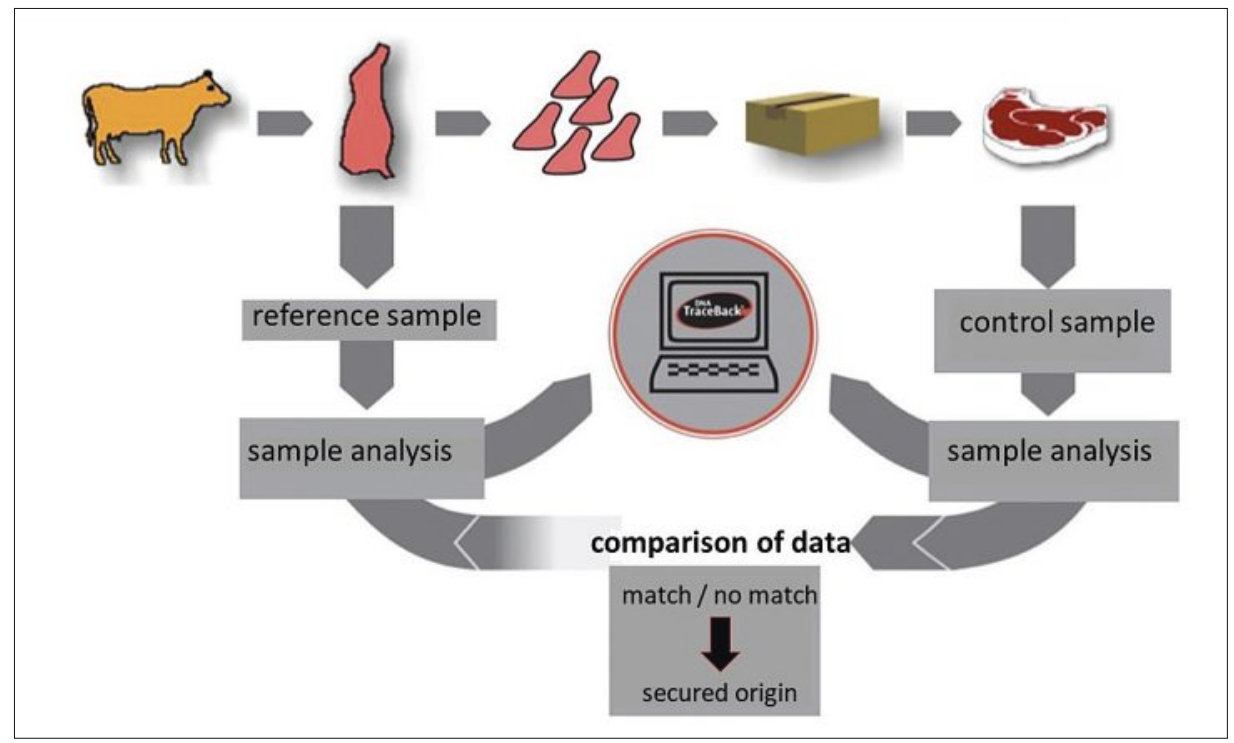

Fig. 1. Structure of the DNA traceability system.

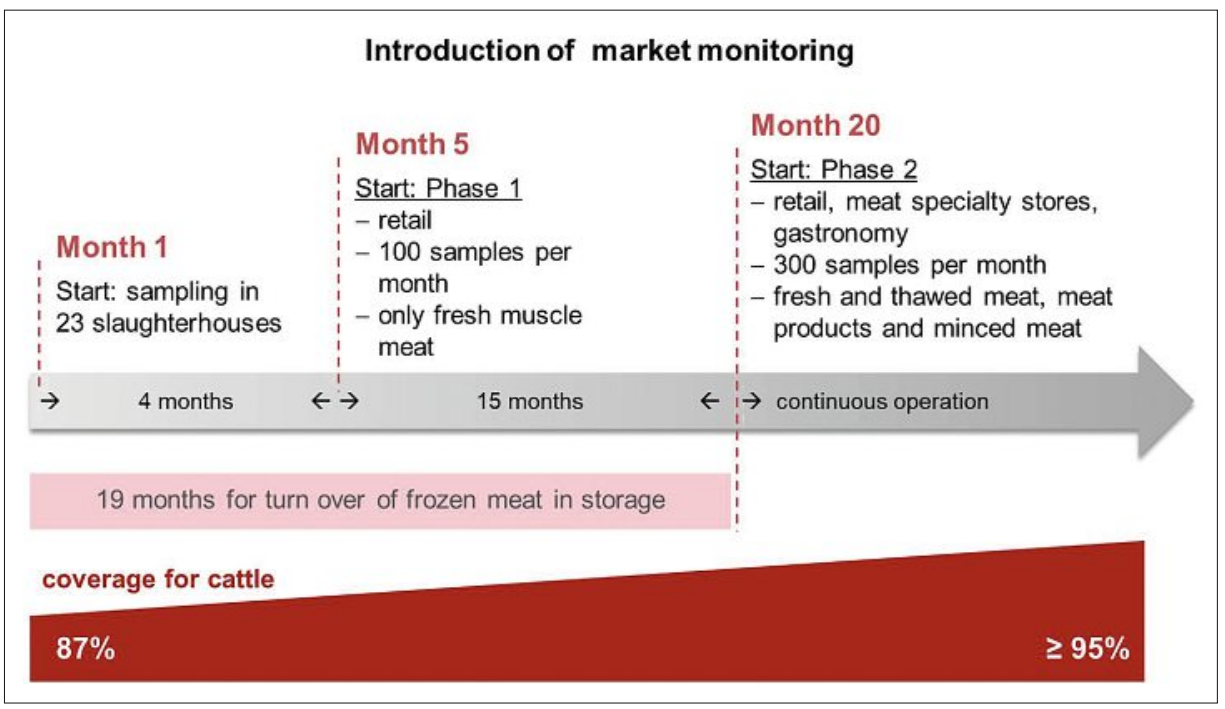

Fig. 2. Market monitoring. onwards, fresh and thawed meat, meat products, minced meat and mixed products can be sampled. The control samples are extended with respect to gastronomy and meat specialty stores (Fig. 2).

A monitoring board will be formed to evaluate multiple no matches (case management), thereby outsourcing the case management to a neutral committee. This should increase acceptance for the traceability system and prevent conflicts of interest.

\section{Coverage}

Characteristic for the traceability programme is that a large percentage of all cattle slaughtered in Switzerland will be sampled in the abattoirs and the DNA will be analysed. For the installation of the system the programme should be started in the 23 largest abattoirs, whereby for cattle already a coverage of around $87 \%$ will be reached. Within one year around 120 medium-sized and smaller enterprises should further be included, aiming at a coverage of $\geq 95 \%$.

For the reference samples, annual sampling of around 600'000 animals of cattle will be taken into account. For the control around 3'600 samples per year are planned to be taken.

\section{Financing}

The financing of the system of DNA traceability is provided by the meat industry, i.e. the costs of the system are covered by the selling of sample carriers to the slaughterhouses. The participating slaughterhouses require a sample carrier for each animal to be sampled and must buy this at the currently defined price of CHF 7.50.

There are additional operating costs due to the sampling process in the participating slaughterhouses depending on their size (ca. CHF 0.22-6.25 per animal).

The board of directors of Proviande has decided that the financing of the system of DNA traceability will have to occur at $100 \%$ via the carcasses through calculation of the meat price, i.e. the slaughterhouses will pass the additional costs completely over to the carcasses. Thus, neither the slaughterhouses nor the producers (livestock suppliers) must bear the costs themselves, but rather the effort becomes part of the cost calculation of the processing companies.

The effects on the final selling price can be estimated at CHF 0.04-0.07 per kilogram beef and CHF $0.08-0.14$ per kilogram veal, respectively. 


\section{Development Prospects}

In principle, the system of DNA traceability serves to verify the origin of Swiss meat. Based on the available database and the unambiguous assignment of the ear tag numbers, in a second step Proviande can offer additional services for the meat industry and selected third parties. This should happen after the start of phase 2 of the market monitoring, as soon as sufficient experience has been gained.

Expansion potential will cover in particular:

- Verification of incoming goods (purchases from third suppliers)

- Verification of label products

- Analyses for the authorities/offices of enforcement

As a further development prospect the aim should be a total system for Swiss livestock. The system of DNA traceability should be upgradeable correspondingly in order to benefit from synergies in the use of DNA profiles in other areas of animal production (in particular in animal breeding).

\section{Conclusion}

The DNA tractability system, which will be introduced into the Swiss meat market in 2018 will set a new standard on a national level. It will prevent false declaration of imported meat as Swiss meat and enhance credibility among the whole value chain and especially for the consumers. Cases of meat fraud as have occasionally occurred in the past can be detected promptly with a reliable scientific method. The program will strengthen the credibility of the Swiss meat business and the consumer confidence can be maintained and deepened.
[1] Proviande, 'Der Fleischmarkt im Überblick 2016', https://www.proviande.ch/de/medien/ page/2017/der-fleischmarkt-2016-im-ueberblick.html

[2] www.proviande.ch

[3] IdentiGEN Ltd., Dublin, Ireland, www.identigen.com

[4] E. P. Cunningham, C. M. Meghen, Rev. Sci. Tech. 2001, 20, 491 . 